\title{
Platelet-derived Growth Factor Signaling and Human Cancer
}

\author{
Jiuhong Yu, Carolyn Ustach and Hyeong-Reh Choi Kim* \\ Department of Pathology, Barbara Ann Karmanos Cancer Institute, Wayne State University, School of Medicine, \\ Detroit, MI 48201, USA
}

Received 18 November 2002

\begin{abstract}
Platelet-derived growth factor (PDGF) is a critical regulator of mesenchymal cell migration and proliferation. The vital functions of PDGFs for angiogenesis, as well as development of kidney, brain, cardiovascular system and pulmonary alveoli during embryogenesis, have been well demonstrated by gene knock-out approaches. Clinical studies reveal that aberrant expression of PDGF and its receptor is often associated with a variety of disorders including atherosclerosis, fibroproliferative diseases of lungs, kidneys and joints, and neoplasia. PDGF contributes to cancer development and progression by both autocrine and paracrine signaling mechanisms. In this review article, important features of the PDGF isoforms and their cell surface receptor subunits are discussed, with regards to signal transduction, PDGF-isoform specific cellular responses, and involvement in angiogensis, and tumorstromal interactions.
\end{abstract}

Keywords: Platelet-derived growth factor, PDGF recepter (PDGF)

\section{Introduction}

Platelet-derived growth factor (PDGF) was described approximately 30 years ago as a major mitogenic component of whole blood, but was absent in cell-free serum. PDGF was purified from the alpha-granules of the platelets, and was thought to be produced mainly by megakaryocytes, the precursor cells of platelets (Kohler and Lipton, 1974; Ross et al., 1974; Westermark and Wasteson, 1976). However, subsequent studies revealed that PDGF is also produced by the epithelium, endothelium, and many other cell types which are in close apposition to mesenchymal cells, which express PDGF receptors. These expression patterns suggest PDGF-

*To whom correspondence should be addressed.

Tel: 1-313-577-2407 or 577-0193; Fax: 1-313-577-0057

E-mail: hrckim@med.wayne.edu mediated paracrine signaling (Ataliotis and Mercola, 1997; DiCorleto and Bowen-Pope, 1983; Bronzert et al., 1990).

PDGF is a potent mitogen for mesenchymal cells including fibroblasts, smooth muscle cells, and glial cells (Ross et al., 1986; Deuel, 1987; Heldin, 1992). PDGF also induces other diverse and important cellular processes including chemotaxis, survival, apoptosis (programmed cell death) and transformation in vitro (Deuel et al., 1982; Deuel et al., 1983; Doolittle et al., 1983; Senior et al., 1983; Waterfield et al., 1983; Williams et al., 1983; Huang et al., 1984; Bejcek et al., 1989; Barres et al., 1992; Kim et al., 1995). These activities correlate with the proposed functional roles of PDGF in vivo during embryonic development, inflammation, and wound healing (Deuel and Huang, 1984; Tzeng et al., 1985; Deuel, 1987; Pierce et al., 1988; Raff et al., 1988; Pierce et al., 1989; Yeh et al., 1991). Additionally, a causative role in tumorigenesis was suggested when $\mathrm{v}$-sis (the oncogene of simian sarcoma virus) was found to be $92 \%$ homologous to PDGF-B. (Deuel et al., 1983; Doolittle et al., 1983; Waterfield et al., 1983; Deuel, 1987). Clinical studies revealed that aberrant expression of PDGF and its receptor was associated with a variety of disorders including atherosclerosis, fibroproliferative diseases of lungs, kidneys and joints, and neoplasia (Deuel et al., 1983; Doolittle et al., 1983; Waterfield et al., 1983; Huang et al., 1984; Ross et al., 1986; Deuel, 1987; Raff et al., 1988; Bejcek et al., 1989; Heldin, 1992; Kim et al., 1994), suggesting a role for PDGF in the development and progression of certain diseases. In this article, we review important features of the PDGF isoforms and their cell surface receptor subunits with regards to signal transduction, PDGF-isoform specific cellular responses, and involvement in human cancer development and progression.

\section{Platelet-derived Growth Factor Isoforms}

Biosynthesis and processing of PDGF isoforms PDGF belongs to the PDGF/VEGF (vascular endothelial growth factor) family, which is characterized by eight strictly conserved cysteine residues with similar spacing in between 
(Joukov et al., 1997; Heldin and Westermark, 1999). The A-, B-, C-, and D-chain genes of PDGF are localized to the chromosomes 7p22, 22q13, 4q31, and 11q22, respectively, and their expression is independently regulated (Tzeng et al., 1985; Deuel, 1987; Raff et al., 1988; Yeh et al., 1991; Heldin, 1992; Betsholtz et al., 2001; LaRochelle et al., 2001; Uutela et al., 2001; Dijkmans et al., 2002). Two forms of the PDGF A-chain, containing 196 and 211 amino acid residues resulting from differential splicing of the transcript, are synthesized, dimerized, proteolytically processed in the $\mathrm{N}$ terminus, and secreted from the cell as a $\sim 30 \mathrm{kDa}$ dimer (Bonthron et al., 1988; Rorsman et al., 1988). The PDGF Bchain encoding 241 amino acid residues is dimerized, processed by additional proteolysis, and secreted as a $24 \mathrm{kDa}$ dimer (Ostman et al., 1988; Ostman et al., 1992). The homodimers $\mathrm{PDGF} \mathrm{AA}, \mathrm{BB}$, and the heterodimer $\mathrm{AB}$ contain three intrachain disulfide bonds made between the $1^{\text {st }} \& 6^{\text {th }}, 3^{\text {rd }}$ $\& 7^{\text {th }}$, and $5^{\text {th }} \& 8^{\text {th }}$ cysteine residues from the $\mathrm{N}$-terminus as diagrammed in Fig. $1 \mathrm{~b}$. The $2^{\text {nd }}$ and $4^{\text {th }}$ cysteine residues are asymmetrically connected by two interchain disulfide bridges (Heldin et al., 1993).

Recently, the PDGF C- and D-chains were discovered in a BLAST search of the expressed-sequence tag (EST) databases at the National Center for Biotechnology Information (Bergsten et al., 2001; LaRochelle et al., 2001; Li et al., 2000). Independently, PDGF $C$ has also been identified as fallotein (Tsai et al., 2000) and spinal-cord-derived growth factor (SCDGF) (Hamada et al., 2000). The full-length PDGF C- and D proteins contain 345 and 370 amino acid residues respectively, and both have a unique two-domain structure with a N-terminal CUB domain and a C-terminal PDGF/ VEGF domain. The CUB domain, composed of approximately 110 amino acids, shares sequence homology with the CUB domains of the complement subcomponents $\mathrm{C} 1 \mathrm{r} / \mathrm{C} 1 \mathrm{~s}$ as well as bone morphogenetic protein 1 (BMP-1) (Bork, 1991). Proforms of PDGF C and D are secreted as an approximately $85 \mathrm{kDa}$ homodimer after cleavage of the $\mathrm{N}$ terminal 22 signal peptide residues. Currently, it is unknown whether PDGF C- and D-chains form heterodimers between each other or with other PDGF chains. Whereas secreted PDGF AA, BB, and AB can readily activate their cell surface receptors, proteolytic removal of the CUB domain is required for the growth factor domain of PDGF CC and DD to activate the cell surface receptors $\alpha$-PDGFR and $\beta$-PDGFR. Interestingly, although phylogenetic analysis of the growth factor domains of PDGF C and D revealed more similarity to VEGFs than to PDGFs, the growth factor domains of PDGF $\mathrm{CC}$ and DD do not activate the VEGF receptors.

While the growth factor domain of PDGF C contains all 8 cysteine residues strictly conserved among VEGF/PDGF family members, the PDGF D growth factor domain lacks the fifth conserved cysteine residue in this motif. In addition to the 8 conserved cysteine residues, the growth factor domain of PDGF $C$ has four additional cysteine residues located between invariant cysteines 3 and 4, 5 and 6,6 and 7 and an additional cysteine after the invariant cysteine 8 . The growth factor domain of PDGF D also bears these additional cysteine residues found in PDGF C, except for the cysteine between invariant 5 and 6 , as shown in Fig. 1a. Previous studies showed that the disulfide bonds between invariant cysteine residues $1 \& 6$, and $3 \& 7$, are critical for the biological activity of PDGF BB, whereas the disulfide bridge between invariant cysteine residues 5 \& 8 is not (Giese et al., 1987; Sauer and Donoghue, 1988; Ostman et al., 1992). Thus, missing the $5^{\text {th }}$ invariant cysteine residue in the PDGF D growth factor domain may not affect its biological activity as a PDGF ligand, although it may alter protein stability and/or its binding affinity due to the changes in three-dimensional structure. Interestingly, it was reported that PDGF DD growth factor domain is a $\sim 3$ fold less efficient competitor than PDGF BB in a ligand binding assay (Bergsten et al., 2001). It should be mentioned that at present it is unknown which cysteine residues in the PDGF $\mathrm{C}$ and $\mathrm{D}$ peptides are utilized for disulfide bonds to form dimers. Detailed structural analysis of PDGF C and D dimers will help us understand common and unique features of these isoforms compared to the previously well characterized PDGF AA and BB.

Functions of PDGFs PDGF is expressed throughout an animals embryo development and adult life. The vital functions of PDGFs during embryonic development have been well demonstrated by gene knock-out approaches \{reviewed in (Betsholtz et al., 2001)\}. PDGF A-deficient mice die either before embryonic day 10 or undergo premature death after birth. Histological analysis of these mice showed loss of alveolar smooth muscle cells resulting in defective pulmonary alveoli development, mesenchymal defects in the skin, and reduced oligodendrocytes in the brain which lead to dysmyelination and motorial defects (Bostrom et al., 1996; Fruttiger et al., 1999). Deletion of the PDGF B gene is lethal during late gestation. Lethality of PDGF-B deficiency is caused by abnormal renal development resulting from the absence of mesangial cells, a major structural and functional component of kidney glomeruli. Lethality is also caused by failure of the pericyte to migrate to the new blood vessels which then leads to abnormal blood vessel formation and defective cardiovascular system development (Leveen $e t$ al., 1994; Soriano, 1994; Lindahl et al., 1997).

Studies of PDGFs and PDGF receptors expression patterns in different tissues during embryogenesis as well as pathological processes have provided clues for differential roles of PDGFs in diverse cellular processes. In development, timing of expression can vary for each PDGF isoform in the same developing organ. For example, analysis of PDGF expression in the developing murine kidney reveal differential timing of expression between PDGF-A and PDGF-C. PDGF$\mathrm{C}$ expression is highest in the early stages of nephron development, while PDGF-A is preferentially expressed in the later stages, even though $\alpha$-PDGFR is expressed throughout development. (Li et al., 2000) Additional to temporal and 
(A)

PDGF-A (195aa)

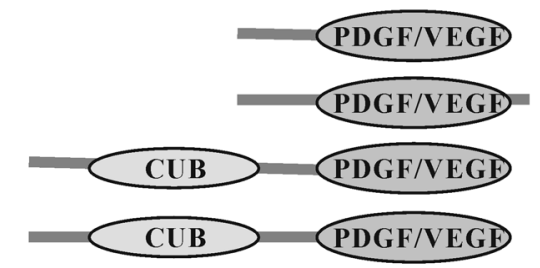

PDGF-B (241 aa)

PDGF-C (345aa)

PDGF-D (370)aa
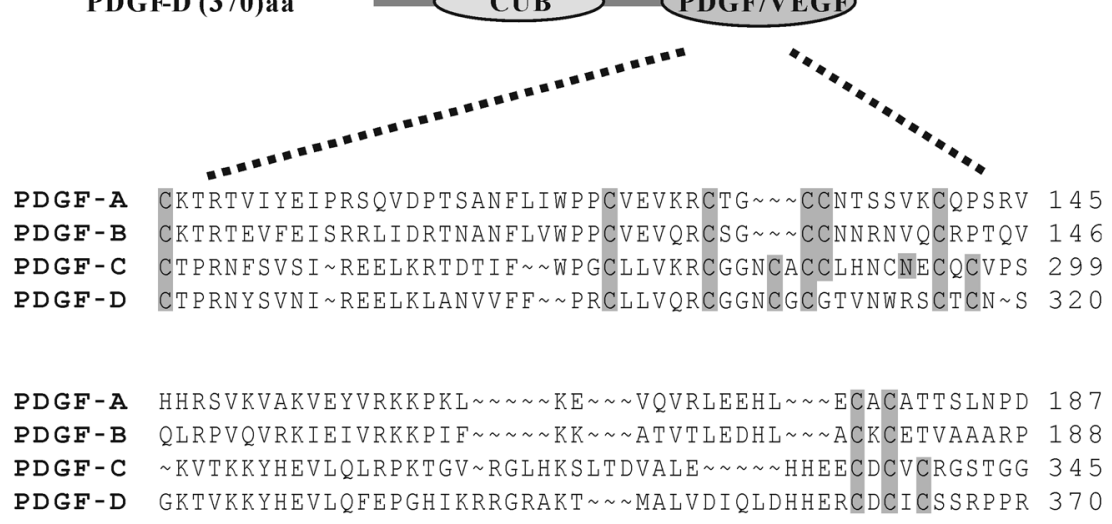

(B)

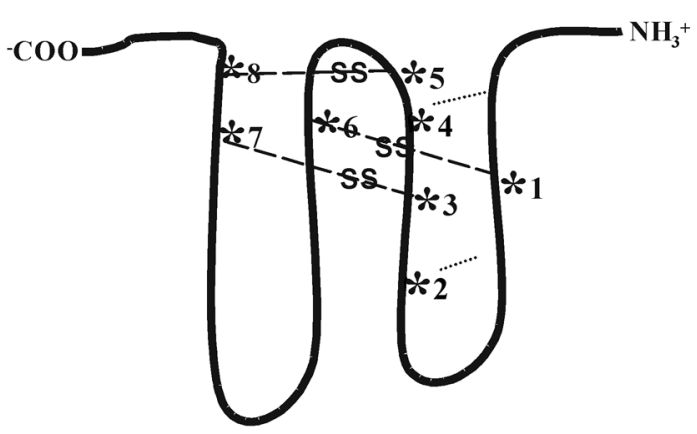

Fig. 1. Comparison of Growth Factor Domains among the PDGF isoforms. (A) Cartoon representation of the domains of each PDGF isoform. Sequence of each PDGF/VEGF domain starts at the first cysteine of the motif. Cysteines shaded in dark gray are the 8 invariant cysteines common to all members of the PDGF/VEGF family members. The $5^{\text {th }}$ invariant cysteine residue has been replaced by glycine in PDGF-D. Residues shaded light gray are additional cysteines conserved among isoforms PDGF-C and PDGF-D. Numbers are in context of the full-length protein of the isoforms. (B) Cartoon of the 3-loop structure of the PDGF-B monomer, illustrating the intrachain disulfide bonds formed between the invariant cysteines 1 and 6, 3 and 7 and 5 and 8. Cysteines 2 and 4 (shaded gray) form interchain disulfide bonds to create the PDGF dimer.

spatial differences in expression, in vitro studies indicate that different PDGF isoforms may induce intracellular signal transduction pathways differently in cells with the same genetic background. For example, although PDGF AA and $\mathrm{BB}$ are equally potent mitogens, only PDGF $\mathrm{BB}$ has transforming ability in murine fibroblasts in vitro (Beckmann et al., 1988; Bejcek et al., 1989; Kim et al., 1994). An important question to be addressed is whether PDGF BB induces unique positive signals for transformation, or if PDGF $\mathrm{AA}$ and $\mathrm{BB}$ differentially regulate negative signaling critical for "fine tuning" of PDGF-mediated cellular processes (This issue is further discussed in the "PDGF receptors and signal transduction" section below).

PDGF, especially AA and BB, exert direct mitogenic and/or chemoattractive activities on mesenchymal cells, such as fibroblast, vascular smooth muscle cells, glial cells, macrophages and chondroncytes, which express high affinity receptors (Ross et al., 1986; Deuel, 1987; Heldin, 1992). In addition, PDGF amplifies its initial proliferative signals by increasing the expression levels of PDGF itself and other mitogens (Clemmons et al., 1981; Clemmons and Van Wyk, 1985; Paulsson et al., 1987). PDGF also regulates the production of collagen (Canalis, 1981; Narayanan and Page, 1983), fibronectin (Blatti et al., 1988), proteoglycan (Schonherr et al., 1991), hyaluronic acid (Heldin et al., 1989) and collagenase (Chua et al., 1985). These results indicate a role for PDGF in active connective tissue remodeling through recruiting essential cellular components and regulating ECM turnover.

PDGF functions as a "competent" factor that regulates the cell cycle during the $\mathrm{G}_{0} / \mathrm{G}_{1}$ transition (Stiles et al., 1979; Pledger et al., 1981). For PDGF-stimulated cells to progress beyond late $G_{1}$ phase and transit the cell cycle and divide, progression factors such as insulin and insulin-like growth factor-1 are required (Stiles, 1983; Olashaw et al., 1987). 


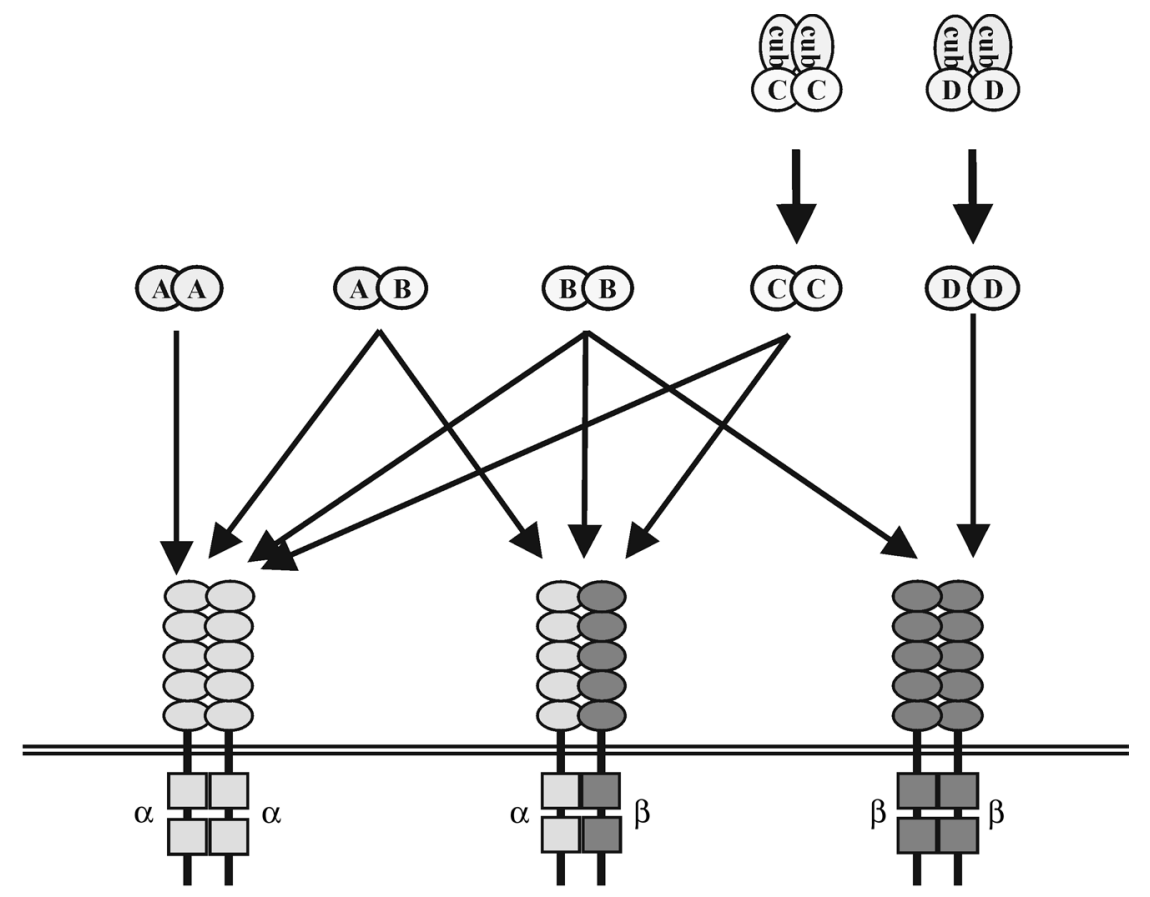

Fig. 2. PDGF dimer interactions with PDGF receptors. Each PDGF homodimer differs in their interactions with the PDGFRs. PDGFAA activates $\alpha \alpha$-PDGFR, while PDGF-BB activates $\alpha \alpha-, \beta \beta$-, or $\beta \beta$-PDGFR. PDGF-CC activates either $\alpha \alpha-$ or $\alpha \beta-P D G F R$, but PDGF-DD can activate only $\beta \beta$-PDGFR. Only one heterodimer, PDGF-AB, has been identified to date. PDGF-AB activates either $\alpha \alpha-$ or $\alpha \beta$-PDGFR

Seemingly paradoxical to PDGFs role in mitogenesis, high levels of PDGF expression have been observed in tissues within unfavorable environments for cell growth, raising the important question of whether the responses of cells to PDGF vary depending upon the genetic programs that can be activated by extracellular factors. In fact, we previously demonstrated that serum-deprived normal rat kidney fibroblast (NRK) cells undergo apoptotic cell death following chronic stimulation with either PDGF AA or PDGF BB. We also showed that PDGF-induced apoptosis is inhibited by cell cycle progression factors such as insulin. (Kim et al., 1995). Consistent with our observation, other investigators have reported during the past decade that constitutive activation of protein-tyrosine kinase receptors, including PDGFR and epidermal growth factor receptor (EGFR), causes growth arrest and/or apoptosis in vitro (Armstrong et al., 1994; Eastman, 1995; Unlu et al., 1998; Kottke et al., 1999). This evidence suggests that polypeptide growth factors in vivo may signal cell fate positively or negatively depending upon intracellular and extracellular signaling context, providing the molecular basis for the checkpoints of growth factor signaling.

\section{Platelet-derived Growth Factor Receptors and Signal Transduction}

PDGF receptors PDGF isoforms exert their cellular effects by activating two structurally related cell surface receptor tyrosine kinases ( $\alpha$-PDGFR and $\beta$-PDGFR). The $\alpha$-PDGFR and $\beta$-PDGFR genes are localized on chromosomes $4 \mathrm{q} 12$ and 5q33, respectively. Both PDGFRs contain five extracellular immunoglobulin-like domains, a transmembrane domain, a juxtamembrane domain, splitted kinase domains, a kinase insert domain, and a cytoplasmic tail. These two receptors share $31 \%$ identity in the ligand binding domain, $27 \%$ identity in the kinase insert and $28 \%$ identity in the C-terminus, whereas they are $85 \%$ and $75 \%$ identical in the two halves of the kinase insert domain (Matsui et al., 1989; Rosenkranz and Kazlauskas, 1999). The three dimeric PDGF receptors $(\alpha \alpha$, $\alpha \beta, \beta \beta$ ) mediate PDGF isoform-specific signal transduction. PDGF AA effectively activates only $\alpha \alpha$-PDGFR, PDGF AB can activate either $\alpha \alpha$-PDGFR or $\alpha \beta$-PDGFR, while PDGF BB activates all three dimeric PDGF receptors (ClaessonWelsh et al., 1988; Matsui et al., 1989; Claesson-Welsh, 1994). The growth factor domain of PDGF CC activates both the $\alpha \alpha$-PDGFR and $\alpha \beta$-PDGFR, and the growth factor domain of PDGF DD activates only the $\beta \beta$-PDGFR (Li et al., 2000; Bergsten et al., 2001; Gilbertson et al., 2001; LaRochelle et al., 2001). At present, it is unclear whether the PDGF DD growth factor domain can activate $\alpha \beta$-PDGFR.

Similar to the PDGF ligands, the critical functions of the PDGF receptors during embryonic development have been well demonstrated by gene targeting approaches \{reviewed in (Betsholtz et al., 2001)\}. Compared to PDGF A- and PDGF B-deficient mice, the phenotype of $\alpha$-PDGFR deficiency revealed unique features including cleft face, spina bifida, and 
skeletal defects, resulting in embryonic death between E8 and E16 (Soriano, 1997). The unique phenotypes of the $\alpha$-PDGFR knockout mouse suggest that PDGF $\mathrm{C}$ may play a unique role during embryonic development through $\alpha$-PDGFR activation. Histological analysis of PDGF B- and $\beta$-PDGFR-deficient mice performed so far revealed identical phenotypes, suggesting that PDGF D-mediated $\beta$-PDGFR signaling may not play a major role during embryonic development. A complete understanding of $\alpha$ - and $\beta$-PDGFRs functions awaits thorough analysis of PDGF C- and D-mediated signal transduction and their cellular effects during embryogenesis as well as both physiological and pathological processes in adults.

PDGFR-mediated intracellular signal transduction Differential interactions of PDGF isoforms with PDGF receptor subunits establish one basis for the diverse PDGF isoform-specific functions. Dimerization and autophosphorylation of PDGFR occur upon receptor-ligand interaction. Phosphorylated tyrosine residues, in the context of specific amino acid residues, interact with Src homology 2 domains (SH2) of intracellular signaling molecules. These include phospholipase $\gamma$ (PLC- $\gamma$ ), Ras GTPase-activating protein (RAS-GAP), p85 subunit of phosphatidylinositol 3kinase (PI-3K), growth-factor receptor-bound protein 2 (Grb 2), Syp (tyrosine-specific phosphatase), Src homology and collagen protein (Shc), Crk ( a group of adaptor proteins) and Src, a family of non-receptor tyrosine kinases (ClaessonWelsh, 1994). These signaling molecules further transduce signal transduction pathways by activating downstream signaling molecules such as mitogen activated protein kinase family members (ERKs, JNKs), and focal adhesion kinase (FAK, a mediator of integrin signaling pathway) among others. These signals enter the nucleus and stimulate expression of a set of immediate-early-response genes that mediate PDGF-induced cellular processes including cell cycle, cell migration, and transformation.

The similarities and differences in the functions of the two PDGFR subunits result from the specific interactions between the flanking amino acid residues of the phosphotyrosine in the PDGF receptor subunit and the $\mathrm{SH} 2$ domain of intracellular signaling molecules (Heidaran et al., 1993; Kazlauskas et al., 1993; Lechleider et al., 1993; Bazenet and Kazlauskas, 1994; Bazenet et al., 1996; DeMali et al., 1997; Yokote et al., 1998; Rosenkranz and Kazlauskas, 1999). Src, PI-3K, and PLC- $\gamma$ bind both receptors with $\mathrm{Src}$ at the juxtamembrane domain, PI-3K at the kinase insert, and PLC- $\gamma$ at the cytoplasmic tail. Only $\beta$-PDGFR, but not $\alpha$-PDGFR, effectively interacts with Ras-GAP, a negative regulator of Ras. Conversely, Crks possess very high binding affinities for $\alpha$-PDGFR, but not for $\beta$-PDGFR. Interestingly, SHP-2 binds to the carboxylterminal of $\alpha$-PDGFR instead of the kinase insert domain of $\beta$-PDGFR.

Although interaction of the above mentioned signaling molecules with PDGF receptors were shown to further

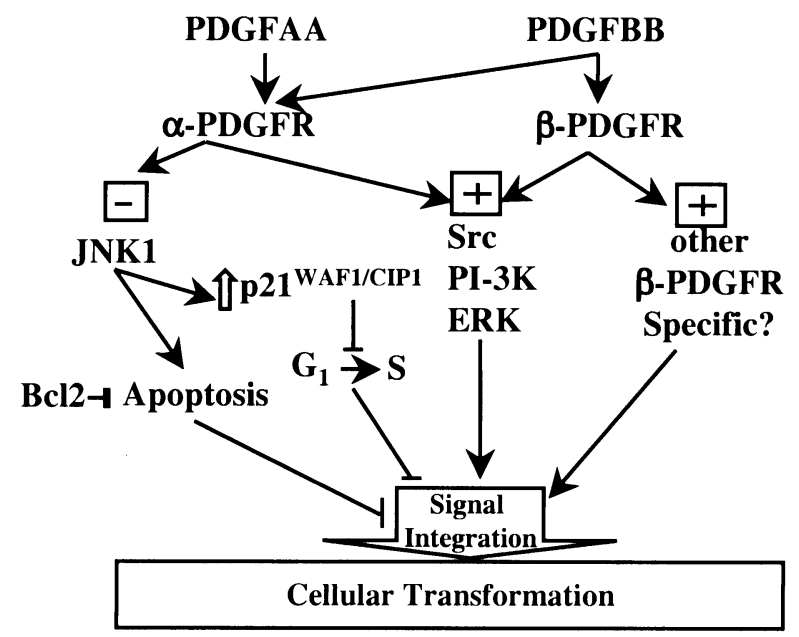

Fig. 3. A Model for PDGF Regulation of Cellular Transformation. The scheme depicts PDGFR-activated signaling molecules (such as JNK, ERK, PI-3K and Src) critical for transformation regulation. PDGF AA or BB activation of $\alpha$ PDGFR induces both pro- and anti-transformation pathways, while PDGF BB activation of $\beta$-PDGFR promotes protransformation pathways. $\alpha$-PDGFR-mediated anti-transformation pathway includes JNK-1 activation which leads to induction of $\mathrm{p} 21^{\mathrm{WAF} / \mathrm{CIP} 1}$ and/or apoptosis. When the pro-apoptotic pathway is downregulated by anti-apoptotic gene products such as Bcl-2, $\alpha$ PDGFR promotes cellular transformation.

activate downstream signaling pathways, little is known about which signaling pathways are $\alpha$ - or $\beta$-PDGFR-specific, and how these signal transduction pathways are agonized or antagonized to regulate specific cellular processes. To address this issue, we previously established NIH3T3 clones in which $\alpha$-PDGFR signaling is inhibited by a dominant-negative $\alpha$ PDGFR, or an anti-sense construct of $\alpha$-PDGFR (Yu et al., 2000). We showed that inhibition of $\alpha$-PDGFR signaling enhanced PDGF BB-mediated phenotypic transformation, suggesting that $\alpha$-PDGFR antagonizes $\beta$-PDGFR-induced transformation. While both $\alpha$ - and $\beta$-receptors effectively activate ERKs, $\alpha$-PDGFR, but not $\beta$-PDGFR, activates stressactivated protein kinase-1/c-Jun $\mathrm{NH}_{2}$-terminal kinase-1 (SAPK1/JNK-1). Inhibition of JNK-1 activity using a dominant-negative JNK-1 mutant markedly enhanced PDGF BB-mediated anchorage-independent cell growth, demonstrating an antagonistic role for JNK-1 in PDGFinduced transformation. These results revealed a striking feature of PDGF signaling: the specificity and the strength of the PDGF-growth signal is modulated by $\alpha$-PDGFR-mediated simultaneous activation of growth stimulatory and inhibitory signals. As depicted in Fig. 3, activation of $\alpha$-PDGFR may transduce both positive and negative signaling for cell transformation, while $\beta$-PDGFR mainly induces positive signaling for cell transformation. PDGF BB activation of both receptors shifts the balance of signaling to favor the transformation pathway, while PDGF AA activation of $\alpha$ - 
PDGFR alone does not. Consistent with this model, we previously demonstrated that $\alpha$-PDGFR activation can result in phenotypic transformation when $\alpha$-PDGFR-mediated negative signaling is inhibited by bcl-2 (Kim et al., 1994). Our on-going studies further show that the $\alpha$-PDGFR/JNK-1 pathway is critical for PDGF-regulation of apoptosis as well as PDGF-induced expression of $\mathrm{p} 21^{\mathrm{WAF} 1 / \mathrm{CIP} 1}$, an inhibitor of cyclin-dependent kinases critical for $\mathrm{G}_{1} / \mathrm{S}$ checkpoint (Yu and Kim, manuscript in preparation). This suggests that the loss of $\alpha$-PDGFR-induced negative signaling (such as JNK-1) may be as critical as gain of positive oncogenic signaling (such as ERKs) for tumor development and/or progression.

$\alpha$-PDGFR-mediated simultaneous activation of both positive and negative signaling has also been demonstrated in cell migration. In smooth muscle cells, PDGF BB induces cell migration more effectively than PDGF AA. Inhibition of $\alpha$ PDGFR using a neutralizing monoclonal antibody to $\alpha$ PDGFR enhanced $\beta$-PDGFR-induced smooth muscle cell migration (Koyama et al., 1994). Additionally, it was shown that $\alpha$-PDGFR has an intrinsic ability to mediate both positive and negative chemotactic signaling (Yokote et al., 1996). In fibroblast cells, however, we previously showed that both $\alpha$ and $\beta$-PDGFRs promote cell migration with equal effectiveness, and their effects are additive (Yu et al., 2001).

Taken together, cell-type and PDGFR subunit specificintracellular signal transduction pathways are responsible for PDGF isoform-specific regulation of diverse cellular processes. Of particular importance, $\alpha$-PDGFR-mediated agonistic and antagonistic activities for cell growth and motility provide a molecular basis for "fine-tuning" of PDGF signaling depending on genetic background of the cells and additional extracellular factors. At present, little is known about signal transduction pathways mediated by PDGF C- and PDGF D-activated PDGFRs. Differences in the affinity and duration of PDGF isoform-binding to the PDGFR subunit may result in subtle, but critical, differences in signal transduction pathways. The unique structure of PDGF $\mathrm{C}$ and $\mathrm{D}$, requiring proteolytic cleavage of the CUB domain to allow growth factor domains to activate PDGFRs, implements another level of regulation in PDGF signaling. Further analysis of overlapping and distinct signal transduction pathways mediated by $\alpha$-PDGFR following interactions with PDGF A or PDGF $\mathrm{C}$, as well as by $\beta$-PDGFR upon binding of PDGF B or PDGF D will lead us to better understanding of PDGF functions in vivo.

\section{PDGF and Human Cancer}

Relevance of PDGF signaling to human tumor progression Studies during the past two decades clearly indicate the significance of PDGF in human tumors including glioma (Hermanson et al., 1992; Plate et al., 1992; Westermark et al., 1995), dermatofibrosarcoma (Shimizu et al., 1999; Greco et al., 2001), neurofibroma (Kadono et al.,
2000), myelomonocytic leukemia (Golub et al., 1994), osteoblastoma (Sulzbacher et al., 2000), and osteosarcoma (Allam et al., 1992; Liang et al., 1996). In vitro, overexpression of the $\mathrm{v}$-sis oncogene product (p28v-sis) or PDGF B in cells that express their receptors enhances transformation, indicating an autocrine mechanism in tumorigenesis (Beckmann et al., 1988; Uhrbom et al., 2000). In accord with the strong transforming ability of $\beta$-PDGFR, most malignant mesothelioma cell lines express $\beta$-PDGFR, whereas normal mesothelial cells predominantly express $\alpha$ PDGFR (Langerak et al., 1996). Unlike $\beta$-PDGFR, in vitro studies showed that $\alpha$-PDGFR transduces both positive and negative signals for cell transformation, and that high $\alpha$ PDGFR or PDGF A expression exerts none or weak transforming ability in normal or pre-malignant cells. However, in clinical studies, $\alpha$-PDGFR as well as PDGF-A expression is more prominent in high-grade tumors such as glioma. (Mapstone, 1991; Hermanson et al., 1996; Rosenkranz and Kazlauskas, 1999; Smith et al., 2000; Yu et al., 2000). Taking in vitro and clinical studies together, we speculate that the perturbations of $\alpha$-PDGFR-mediated negative signaling may occur and accumulate from the early stages of tumor progression in some tumors (analogous to tumor promoters), and at later stages, $\alpha$-PDGFR signaling mainly promotes tumor cell growth and disease progression.

In addition to the autocrine mechanism, recent studies revealed a critical role for paracrine PDGF signaling in carcinogenesis through the regulation of epithelial-stromal interactions. Using nude mice, it was demonstrated that PDGF activation of stromal cells results in tumorigenic conversion of immortal human keratinocytes (Skobe and Fusenig, 1998). Mounting evidence suggests that aberrant interaction between stroma and epithelium is critical for the neoplastic progression of breast epithelium (Zoltowska, 1997; Moinfar et al., 2000). Genetic alterations occur both in epithelial and mesenchymal cells of mammary carcinoma (Moinfar et al., 2000). Furthermore, evidence suggests that genetic alterations in the stromal cells may precede genetic changes in the epithelial cells (Moinfar et al., 2000). Enhanced PDGF immunostaining was detected in soft tissue tumors and advanced breast tumors (Bronzert et al., 1987; Palman et al., 1992; Seymour and Bezwoda, 1994; Coltrera et al., 1995). The significance of PDGF signaling for breast epithelial-stromal interaction was supported by in situ hybridization and immunohistochemical analysis. Expression of PDGF B-protein and mRNA was restricted to the breast epithelium and tumor cells, whereas membranous PDGF receptor immunostaining was detected in stromal cell populations in all of the breast tissues examined (Coltrera et al., 1995). PDGF receptor staining was particularly localized in the periepithelial stroma of breast carcinoma, suggesting a paracrine stimulation of adjacent stromal tissue by breast tumor cells (Coltrera et al., 1995). Furthermore, PDGF was shown to initiate the human breast carcinoma desmoplasia (Shao et al., 2000; Walker, 2001). Similar to breast cancer, paracrine mechanisms were also 
observed in colorectal cancer and small cell lung carcinoma (Kawai et al., 1997; Sundberg et al., 1997). The significance of PDGF signaling in prostate cancer is also well recognized, and a multi-institutional phase II study was successfully completed to test the efficacy of a PDGF receptor inhibitor for patients with hormone-refractory cancer (Ko et al., 2001). Taken together, it is clear that PDGF signaling is critical for the development of many types of human cancers.

PDGFs' role in angiogenesis and tumor metastasis The fatal phenotypes of PDGF- or PDGFR-deficient mice include cardiovascular and hematological defects. PDGFs produced by endothelial cells in vessels promote recruitment and proliferation of vascular smooth muscle cells/pericyte progenitors expressing PDGFR (Betsholtz et al., 2001). Chemotactic and mitogenic activities mediated by the PDGF/ PDGFR paracrine signaling loop are crucial for the formation, branching and maintenance of blood vessels. As in embryogenesis, PDGF plays a critical role for angiogenesis in human tumors. Tumor angiogenesis, required for tumor outgrowth and metastasis, is a complex and highly regulated process involving many different cell types and extracellular factors. Endothelial cells and smooth muscle cells are the major components of blood vessels, and VEGF/PDGF super family members are among the critical mediators of tumor angiogenesis. Clinical studies revealed a correlation between vascular counts and expression frequency of VEGF and PDGF in tumors (Anan et al., 1996). PDGFs directly and indirectly stimulate the angiogenic processes. PDGF released by the tumor cells induce migration of endothelial cells and vascular smooth muscle cells (vSMC), and also stimulate proliferation of these cells, suggesting a direct role of PDGFs in angiogenesis (Thommen et al., 1997). PDGFs were shown to induce transcription and secretion of VEGF by $\beta$-PDGFR expressing endothelial cells, suggesting an indirect role for PDGF induced angiogenesis (Wang et al., 1999). PDGFs also mediate the paracrine signaling loop between endothelial cells and $\mathrm{vSMC} /$ pericytes during tumor angiogenic processes. While PDGF-BB, -AB, and the growth factor domain of PDGF-CC induce indistinguishable angiogenic responses in mouse cornea assay, PDGF-AA stimulates only a weak response (Cao et al., 2002). This suggests that $\alpha$-PDGFR and $\beta$-PDGFR may differently regulate angiogenic processes. Interestingly, $\alpha$-PDGFR, a pro-angiogenic component, was shown to inhibit basic fibroblast growth factor-mediated angiogenesis in the chick embryo chorioallantoic membrane assay and also in matrigel plugs subcutaneously injected in mice (De Marchis et al., 2002). This re-emphasizes the ability of the $\alpha$-PDGFR to simultaneously activate both agonistic and antagonistic signals for a specific cellular process.

The ability of tumor cells to colonize distant organs is determined by the inherent metastatic ability of cancer cells including inducibility of angiogenesis, invasiveness, motility, and increased cell survival. Importantly, it has been well recognized that certain types of cancer cells have preferred end target organs for metastasis. For example, breast cancers cells colonize preferentially to the lung, liver and bone, while the bone is the most common organ of prostate cancer cell metastasis (Yoneda, 1998; Cher, 2001). This suggests that interactions between cancer cells and the host environment of the end organ are also critical for directing cancer cells to the metastatic site, allowing them to survive and colonize the organ. Considering that PDGFs released by the tumor cells are among the potent chemoattractants and mitogens for host mesenchymal cells, it may be reasonable to speculate PDGFs roles for cancer metastasis at the preferential organ sites. This is an under-investigated, but potentially critical, area of PDGF research.

\section{References}

Allam, M., Martinet, N. and Martinet, Y. (1992) Differential migratory response of U-2 OS osteosarcoma cell to the various forms of platelet-derived growth factor. Biochimie 74, 183-186.

Anan, K., Morisaki, T., Katano, M., Ikubo, A., Kitsuki, H., Uchiyama, A., Kuroki, S., Tanaka, M. and Torisu, M. (1996) Vascular endothelial growth factor and platelet-derived growth factor are potential angiogenic and metastatic factors in human breast cancer. Surgery 119, 333-339.

Armstrong, D. K., Kaufmann, S. H., Ottaviano, Y. L., Furuya, Y., Buckley, J. A., Isaacs, J. T., and Davidson, N. E. (1994) Epidermal growth factor-mediated apoptosis of MDA-MB-468 human breast cancer cells. Cancer Res. 54, 5280-5283.

Ataliotis, P. and Mercola, M. (1997). Distribution and functions of platelet-derived growth factors and their receptors during embryogenesis. Int. Rev. Cytol. 172, 95-127.

Barres, B. A., Hart, I. K., Coles, H. S., Burne, J. F., Voyvodic, J. T., Richardson, W. D. and Raff, M. C. (1992) Cell death and control of cell survival in the oligodendrocyte lineage. Cell $\mathbf{7 0}$, 31-46.

Bazenet, C. E., Gelderloos, J. A. and Kazlauskas, A. (1996) Phosphorylation of tyrosine 720 in the platelet-derived growth factor alpha receptor is required for binding of Grb2 and SHP2 but not for activation of Ras or cell proliferation. Mol. Cell. Biol. 16, 6926-6936.

Bazenet, C. E. and Kazlauskas, A. (1994) The PDGF receptor alpha subunit activates p21ras and triggers DNA synthesis without interacting with rasGAP. Oncogene 9, 517-525.

Beckmann, M. P., Betsholtz, C., Heldin, C. H., Westermark, B., Di Marco, E., Di Fiore, P. P., Robbins, K. C. and Aaronson, S. A. (1988) Comparison of biological properties and transforming potential of human PDGF-A and PDGF-B chains. Science 241, 1346-1349.

Bejcek, B. E., Li, D. Y., and Deuel, T. F. (1989) Transformation by $\mathrm{v}$-sis occurs by an internal autoactivation mechanism. Science 245, 1496-1499.

Bergsten, E., Uutela, M., Li, X., Pietras, K., Ostman, A., Heldin, C. H., Alitalo, K., and Eriksson, U. (2001) PDGF-D is a specific, protease-activated ligand for the PDGF beta-receptor. Nature Cell. Biol. 3, 512-516.

Betsholtz, C., Karlsson, L., and Lindahl, P. (2001) Developmental roles of platelet-derived growth factors. Bioessays 23, 494-507. 
Blatti, S. P., Foster, D. N., Ranganathan, G., Moses, H. L., and Getz, M. J. (1988) Induction of fibronectin gene transcription and mRNA is a primary response to growth-factor stimulation of AKR-2B cells. Proc. Natl. Acad. Sci. USA 85, 1119-1123.

Bonthron, D. T., Morton, C. C., Orkin, S. H., and Collins, T. (1988) Platelet-derived growth factor A chain: gene structure, chromosomal location, and basis for alternative mRNA splicing. Proc. Natl. Acad. Sci. USA 85, 1492-1496.

Bork, P. (1991) Complement components $\mathrm{C} 1 \mathrm{r} / \mathrm{C} 1 \mathrm{~s}$, bone morphogenic protein 1 and Xenopus laevis developmentally regulated protein UVS.2 share common repeats. FEBS Lett. 282, 9-12.

Bostrom, H., Willetts, K., Pekny, M., Leveen, P., Lindahl, P., Hedstrand, H., Pekna, M., Hellstrom, M., Gebre-Medhin, S., Schalling, M., et al. (1996) PDGF-A signaling is a critical event in lung alveolar myofibroblast development and alveogenesis. Cell 85, 863-873.

Bronzert, D. A., Bates, S. E., Sheridan, J. P., Lindsey, R., Valverius, E. M., Stampfer, M. R., Lippman, M. E., and Dickson, R. B. (1990) Transforming growth factor-beta induces platelet-derived growth factor (PDGF) messenger RNA and PDGF secretion while inhibiting growth in normal human mammary epithelial cells. Mol. Endocrinol. 4, 981-989.

Bronzert, D. A., Pantazis, P., Antoniades, H. N., Kasid, A., Davidson, N., Dickson, R. B., and Lippman, M. E. (1987) Synthesis and secretion of platelet-derived growth factor by human breast cancer cell lines. Proc. Natl. Acad. Sci. USA 84, 5763-5767.

Canalis, E. (1981) Effect of platelet-derived growth factor on DNA and protein synthesis in cultured rat calvaria. Metabolism 30, 970-975.

Cao, R., Brakenhielm, E., Li, X., Pietras, K., Widenfalk, J., Ostman, A., Eriksson, U., and Cao, Y. (2002) Angiogenesis stimulated by PDGF-CC, a novel member in the PDGF family, involves activation of PDGFR-alphaalpha and -alphabeta receptors. FASEB J. 16, 1575-1583.

Cher, M. L. (2001) Mechanisms governing bone metastasis in prostate cancer. Curr. Opin. Urol. 11, 483-488.

Chua, C. C., Geiman, D. E., Keller, G. H., and Ladda, R. L. (1985) Induction of collagenase secretion in human fibroblast cultures by growth promoting factors. J. Biol. Chem. 260, 5213-5216.

Claesson-Welsh, L. (1994) Platelet-derived growth factor receptor signals. J. Biol. Chem. 269, 32023-32026.

Claesson-Welsh, L., Eriksson, A., Moren, A., Severinsson, L., Ek, B., Ostman, A., Betsholtz, C., and Heldin, C. H. (1988) cDNA cloning and expression of a human platelet-derived growth factor (PDGF) receptor specific for B-chain-containing PDGF molecules. Mol. Cell. Biol. 8, 3476-3486.

Clemmons, D. R., Underwood, L. E. and Van Wyk, J. J. (1981) Hormonal control of immunoreactive somatomedin production by cultured human fibroblasts. J. Clin. Invest. 67, 10-19.

Clemmons, D. R. and Van Wyk, J. J. (1985) Evidence for a functional role of endogenously produced somatomedinlike peptides in the regulation of DNA synthesis in cultured human fibroblasts and porcine smooth muscle cells. J. Clin. Invest. 75, 1914-1918

Coltrera, M. D., Wang, J., Porter, P. L. and Gown, A. M. (1995) Expression of platelet-derived growth factor B-chain and the platelet-derived growth factor receptor beta subunit in human breast tissue and breast carcinoma. Cancer Res. 55, 2703-2708.

De Marchis, F., Ribatti, D., Giampietri, C., Lentini, A., Faraone, D., Scoccianti, M., Capogrossi, M. C. and Facchiano, A. (2002) Platelet-derived growth factor inhibits basic fibroblast growth factor angiogenic properties in vitro and in vivo through its alpha receptor. Blood 99, 2045-2053.

DeMali, K. A., Whiteford, C. C., Ulug, E. T. and Kazlauskas, A. (1997) Platelet-derived growth factor-dependent cellular transformation requires either phospholipase Cgamma or phosphatidylinositol 3 kinase. J. Biol. Chem. 272, 9011-9018.

Deuel, T. F. (1987) Polypeptide growth factors: roles in normal and abnormal cell growth. Annu. Rev. Cell. Biol. 3, 443-492.

Deuel, T. F. and Huang, J. S. (1984) Roles of growth factor activities in oncogenesis. Blood 64, 951-958.

Deuel, T. F., Huang, J. S., Huang, S. S., Stroobant, P. and Waterfield, M. D. (1983) Expression of a platelet-derived growth factor-like protein in simian sarcoma virus transformed cells. Science 221, 1348-1350.

Deuel, T. F., Senior, R. M., Huang, J. S. and Griffin, G. L. (1982) Chemotaxis of monocytes and neutrophils to platelet-derived growth factor. J. Clin. Invest. 69, 1046-1049.

DiCorleto, P. E. and Bowen-Pope, D. F. (1983) Cultured endothelial cells produce a platelet-derived growth factor-like protein. Proc. Natl. Acad. Sci. USA 80, 1919-1923.

Dijkmans, J., Xu, J., Masure, S., Dhanaraj, S., Gosiewska, A., Geesin, J., Sprengel, J., Harris, S., Verhasselt, P., Gordon, R. and Yon, J. (2002) Characterization of platelet-derived growth factor-C (PDGF-C): expression in normal and tumor cells, biological activity and chromosomal localization. Int. $J$. Biochem. Cell. Biol. 34, 414-426.

Doolittle, R. F., Hunkapiller, M. W., Hood, L. E., Devare, S. G., Robbins, K. C., Aaronson, S. A. and Antoniades, H. N. (1983) Simian sarcoma virus onc gene, $\mathrm{v}$-sis, is derived from the gene (or genes) encoding a platelet-derived growth factor. Science 221, 275-277.

Eastman, A. (1995) Survival factors, intracellular signal transduction, and the activation of endonucleases in apoptosis. Semin. Cancer Biol. 6, 45-52.

Fruttiger, M., Karlsson, L., Hall, A. C., Abramsson, A., Calver, A. R., Bostrom, H., Willetts, K., Bertold, C. H., Heath, J. K., Betsholtz, C. and Richardson, W. D. (1999) Defective oligodendrocyte development and severe hypomyelination in PDGF-A knockout mice. Development 126, 457-467.

Giese, N. A., Robbins, K. C. and Aaronson, S. A. (1987) The role of individual cysteine residues in the structure and function of the v-sis gene product. Science 236, 1315-1318.

Gilbertson, D. G., Duff, M. E., West, J. W., Kelly, J. D., Sheppard, P. O., Hofstrand, P. D., Gao, Z., Shoemaker, K., Bukowski, T. R., Moore, M., et al. (2001) Platelet-derived growth factor C (PDGF-C), a novel growth factor that binds to PDGF alpha and beta receptor. J. Biol. Chem. 276, 2740627414.

Golub, T. R., Barker, G. F., Lovett, M. and Gilliland, D. G. (1994) Fusion of PDGF receptor beta to a novel ets-like gene, tel, in chronic myelomonocytic leukemia with $\mathrm{t}(5 ; 12)$ chromosomal translocation. Cell 77, 307-316.

Greco, A., Roccato, E., Miranda, C., Cleris, L., Formelli, F. and Pierotti, M. A. (2001) Growth-inhibitory effect of STI571 on cells transformed by the COL1A1/PDGFB rearrangement. Int. J. Cancer 92, 354-360. 
Hamada, T., Ui-Tei, K. and Miyata, Y. (2000) A novel gene derived from developing spinal cords, SCDGF, is a unique member of the PDGF/VEGF family. FEBS Lett. 475, 97-102.

Heidaran, M. A., Beeler, J. F., Yu, J. C., Ishibashi, T., LaRochelle, W. J., Pierce, J. H. and Aaronson, S. A. (1993) Differences in substrate specificities of alpha and beta platelet-derived growth factor (PDGF) receptors. Correlation with their ability to mediate PDGF transforming functions. J. Biol. Chem. 268, 9287-9295.

Heldin, C. H. (1992) Structural and functional studies on plateletderived growth factor. $E M B O \mathrm{~J} . \mathbf{1 1}, 4251-4259$.

Heldin, C. H., Ostman, A. and Westermark, B. (1993) Structure of platelet-derived growth factor: implications for functional properties. Growth Factors 8, 245-252.

Heldin, C. H. and Westermark, B. (1999) Mechanism of action and in vivo role of platelet-derived growth factor. Physiol. Rev. 79, 1283-1316.

Heldin, P., Laurent, T. C. and Heldin, C. H. (1989) Effect of growth factors on hyaluronan synthesis in cultured human fibroblasts. Biochem. J. 258, 919-922.

Hermanson, M., Funa, K., Hartman, M., Claesson-Welsh, L., Heldin, C. H., Westermark, B. and Nister, M. (1992) Plateletderived growth factor and its receptors in human glioma tissue: expression of messenger RNA and protein suggests the presence of autocrine and paracrine loops. Cancer Res. 52, 3213-3219.

Hermanson, M., Funa, K., Koopmann, J., Maintz, D., Waha, A., Westermark, B., Heldin, C. H., Wiestler, O. D., Louis, D. N., von Deimling, A. and Nister, M. (1996) Association of loss of heterozygosity on chromosome $17 \mathrm{p}$ with high platelet-derived growth factor alpha receptor expression in human malignant gliomas. Cancer Res. 56, 164-171.

Huang, J. S., Huang, S. S. and Deuel, T. F. (1984) Transforming protein of simian sarcoma virus stimulates autocrine growth of SSV-transformed cells through PDGF cell-surface receptors. Cell 39, 79-87.

Joukov, V., Kaipainen, A., Jeltsch, M., Pajusola, K., Olofsson, B., Kumar, V., Eriksson, U. and Alitalo, K. (1997) Vascular endothelial growth factors VEGF-B and VEGF-C. J. Cell Physiol. 173, 211-215.

Kadono, T., Kikuchi, K., Nakagawa, H. and Tamaki, K. (2000) Expressions of various growth factors and their receptors in tissues from neurofibroma. Dermatology 201, 10-14.

Kawai, T., Hiroi, S. and Torikata, C. (1997) Expression in lung carcinomas of platelet-derived growth factor and its receptors. Lab. Invest. 77, 431-436.

Kazlauskas, A., Feng, G. S., Pawson, T. and Valius, M. (1993) The $64-\mathrm{kDa}$ protein that associates with the platelet-derived growth factor receptor beta subunit via Tyr-1009 is the SH2containing phosphotyrosine phosphatase Syp. Proc. Natl. Acad. Sci. USA 90, 6939-6943.

Kim, H. R., Upadhyay, S., Korsmeyer, S. and Deuel, T. F. (1994) Platelet-derived growth factor (PDGF) B and A homodimers transform murine fibroblasts depending on the genetic background of the cell. J. Biol. Chem. 269, 30604-30608.

Kim, H. R., Upadhyay, S., Li, G., Palmer, K. C. and Deuel, T. F. (1995) Platelet-derived growth factor induces apoptosis in growth-arrested murine fibroblasts. Proc. Natl. Acad. Sci. USA 92, 9500-9504.

Ko, Y. J., Small, E. J., Kabbinavar, F., Chachoua, A., Taneja, S.,
Reese, D., DePaoli, A., Hannah, A., Balk, S. P. and Bubley, G. J. (2001) A multi-institutional phase ii study of SU101, a platelet-derived growth factor receptor inhibitor, for patients with hormone-refractory prostate cancer. Clin. Cancer Res. 7, 800-805.

Kohler, N. and Lipton, A. (1974) Platelets as a source of fibroblast growth-promoting activity. Exp. Cell. Res. 87, 297-301.

Kottke, T. J., Blajeski, A. L., Martins, L. M., Mesner, P. W., Jr., Davidson, N. E., Earnshaw, W. C., Armstrong, D. K. and Kaufmann, S. H. (1999) Comparison of paclitaxel-, 5-fluoro-2'deoxyuridine-, and epidermal growth factor (EGF)-induced apoptosis. Evidence for EGF-induced anoikis. J. Biol. Chem. 274, 15927-15936.

Koyama, N., Hart, C. E. and Clowes, A. W. (1994) Different functions of the platelet-derived growth factor-alpha and -beta receptors for the migration and proliferation of cultured baboon smooth muscle cells. Circ. Res. 75, 682-691.

Langerak, A. W., van der Linden-van Beurden, C. A. and Versnel, M. A. (1996) Regulation of differential expression of plateletderived growth factor alpha- and beta-receptor mRNA in normal and malignant human mesothelial cell lines. Biochim. Biophys. Acta 1305, 63-70.

LaRochelle, W. J., Jeffers, M., McDonald, W. F., Chillakuru, R. A., Giese, N. A., Lokker, N. A., Sullivan, C., Boldog, F. L., Yang, M., Vernet, C., et al. (2001) PDGF-D, a new proteaseactivated growth factor. Nat. Cell. Biol. 3, 517-521.

Lechleider, R. J., Freeman, R. M., Jr. and Neel, B. G. (1993) Tyrosyl phosphorylation and growth factor receptor association of the human corkscrew homologue, SH-PTP2. J. Biol. Chem. 268, 13434-13438.

Leveen, P., Pekny, M., Gebre-Medhin, S., Swolin, B., Larsson, E. and Betsholtz, C. (1994) Mice deficient for PDGF B show renal, cardiovascular, and hematological abnormalities. Genes Dev. 8, 1875-1887.

Li, X., Ponten, A., Aase, K., Karlsson, L., Abramsson, A., Uutela, M., Backstrom, G., Hellstrom, M., Bostrom, H., Li, H., et al. (2000) PDGF-C is a new protease-activated ligand for the PDGF alpha-receptor. Nature Cell. Biol. 2, 302-309.

Liang, Y., Robinson, D. F., Dennig, J., Suske, G. and Fahl, W. E. (1996) Transcriptional regulation of the SIS/PDGF-B gene in human osteosarcoma cells by the Sp family of transcription factors. J. Biol. Chem. 271, 11792-11797.

Lindahl, P., Johansson, B. R., Leveen, P. and Betsholtz, C. (1997) Pericyte loss and microaneurysm formation in PDGF-Bdeficient mice. Science 277, 242-245.

Mapstone, T. B. (1991) Expression of platelet-derived growth factor and transforming growth factor and their correlation with cellular morphology in glial tumors. J. Neurosurg. 75, 447-451.

Matsui, T., Heidaran, M., Miki, T., Popescu, N., La Rochelle, W., Kraus, M., Pierce, J. and Aaronson, S. (1989) Isolation of a novel receptor cDNA establishes the existence of two PDGF receptor genes. Science 243, 800-804.

Moinfar, F., Man, Y. G., Arnould, L., Bratthauer, G. L., Ratschek, M. and Tavassoli, F. A. (2000) Concurrent and independent genetic alterations in the stromal and epithelial cells of mammary carcinoma: implications for tumorigenesis. Cancer Res. 60, 2562-2566.

Narayanan, A. S. and Page, R. C. (1983) Biosynthesis and regulation of type $\mathrm{V}$ collagen in diploid human fibroblasts. $J$. Biol. Chem. 258, 11694-11699. 
Olashaw, N. E., Van Wyk, J. J. and Pledger, W. J. (1987) Control of late $\mathrm{G} 0 / \mathrm{G} 1$ progression and protein modification by $\mathrm{SmC} /$ IGF I. Am. J. Physiol. 253, 575-579.

Ostman, A., Rall, L., Hammacher, A., Wormstead, M. A., Coit, D., Valenzuela, P., Betsholtz, C., Westermark, B. and Heldin, C. H. (1988) Synthesis and assembly of a functionally active recombinant platelet-derived growth factor $\mathrm{AB}$ heterodimer. $J$. Biol. Chem. 263, 16202-16208.

Ostman, A., Thyberg, J., Westermark, B. and Heldin, C. H. (1992) PDGF-AA and PDGF-BB biosynthesis: proprotein processing in the Golgi complex and lysosomal degradation of PDGF-BB retained intracellularly. J. Cell. Biol. 118, 509-519.

Palman, C., Bowen-Pope, D. F. and Brooks, J. J. (1992) Plateletderived growth factor receptor (beta-subunit) immunoreactivity in soft tissue tumors. Lab. Invest. 66, 108-115.

Paulsson, Y., Hammacher, A., Heldin, C. H. and Westermark, B. (1987) Possible positive autocrine feedback in the prereplicative phase of human fibroblasts. Nature 328, 715-717.

Pierce, G. F., Mustoe, T. A., Lingelbach, J., Masakowski, V. R., Griffin, G. L., Senior, R. M. and Deuel, T. F. (1989) Plateletderived growth factor and transforming growth factor-beta enhance tissue repair activities by unique mechanisms. J. Cell. Biol. 109, 429-440.

Pierce, G. F., Mustoe, T. A., Senior, R. M., Reed, J., Griffin, G. L., Thomason, A. and Deuel, T. F. (1988) In vivo incisional wound healing augmented by platelet-derived growth factor and recombinant c-sis gene homodimeric proteins. J. Exp. Med. 167, 974-987.

Plate, K. H., Breier, G., Farrell, C. L. and Risau, W. (1992) Platelet-derived growth factor receptor-beta is induced during tumor development and upregulated during tumor progression in endothelial cells in human gliomas. Lab. Invest. 67, 529-534.

Pledger, W. J., Hart, C. A., Locatell, K. L. and Scher, C. D. (1981) Platelet-derived growth factor-modulated proteins: constitutive synthesis by a transformed cell line. Proc. Natl. Acad. Sci. USA 78, 4358-4362.

Raff, M. C., Lillien, L. E., Richardson, W. D., Burne, J. F. and Noble, M. D. (1988) Platelet-derived growth factor from astrocytes drives the clock that times oligodendrocyte development in culture. Nature 333, 562-565.

Rorsman, F., Bywater, M., Knott, T. J., Scott, J. and Betsholtz, C. (1988) Structural characterization of the human platelet-derived growth factor A-chain cDNA and gene: alternative exon usage predicts two different precursor proteins. Mol. Cell. Biol. 8, 571-577.

Rosenkranz, S. and Kazlauskas, A. (1999) Evidence for distinct signaling properties and biological responses induced by the PDGF receptor alpha and beta subtypes. Growth Factors 16, 201-216.

Ross, R., Glomset, J., Kariya, B. and Harker, L. (1974) A plateletdependent serum factor that stimulates the proliferation of arterial smooth muscle cells in vitro. Proc. Natl. Acad. Sci. USA 71, 1207-1210.

Ross, R., Raines, E. W. and Bowen-Pope, D. F. (1986) The biology of platelet-derived growth factor. Cell 46, 155-169.

Sauer, M. K. and Donoghue, D. J. (1988) Identification of nonessential disulfide bonds and altered conformations in the $\mathrm{v}$ sis protein, a homolog of the $\mathrm{B}$ chain of platelet-derived growth factor. Mol. Cell. Biol. 8, 1011-1018.

Schonherr, E., Jarvelainen, H. T., Sandell, L. J. and Wight, T. N.
(1991) Effects of platelet-derived growth factor and transforming growth factor-beta 1 on the synthesis of a large versican-like chondroitin sulfate proteoglycan by arterial smooth muscle cells. J. Biol. Chem. 266, 17640-17647.

Senior, R. M., Griffin, G. L., Huang, J. S., Walz, D. A. and Deuel, T. F. (1983) Chemotactic activity of platelet alpha granule proteins for fibroblasts. J. Cell. Biol. 96, 382-385.

Seymour, L. and Bezwoda, W. R. (1994) Positive immunostaining for platelet derived growth factor (PDGF) is an adverse prognostic factor in patients with advanced breast cancer. Breast Cancer Res. Treat. 32, 229-233.

Shao, Z. M., Nguyen, M. and Barsky, S. H. (2000) Human breast carcinoma desmoplasia is PDGF initiated. Oncogene 19, 43374345.

Shimizu, A., O’Brien, K. P., Sjoblom, T., Pietras, K., Buchdunger, E., Collins, V. P., Heldin, C. H., Dumanski, J. P. and Ostman, A. (1999) The dermatofibrosarcoma protuberans-associated collagen type Ialpha1/platelet-derived growth factor (PDGF) Bchain fusion gene generates a transforming protein that is processed to functional PDGF-BB. Cancer Res. 59, 3719-3723.

Skobe, M. and Fusenig, N. E. (1998) Tumorigenic conversion of immortal human keratinocytes through stromal cell activation. Proc. Natl. Acad. Sci. USA 95, 1050-1055.

Smith, J. S., Wang, X. Y., Qian, J., Hosek, S. M., Scheithauer, B. W., Jenkins, R. B. and James, C. D. (2000) Amplification of the platelet-derived growth factor receptor-A (PDGFRA) gene occurs in oligodendrogliomas with grade IV anaplastic features. J. Neuropathol. Exp. Neurol. 59, 495-503.

Soriano, P. (1994) Abnormal kidney development and hematological disorders in PDGF beta-receptor mutant mice. Genes Dev. 8, 1888-1896.

Soriano, P. (1997) The PDGF alpha receptor is required for neural crest cell development and for normal patterning of the somites. Development 124, 2691-2700.

Stiles, C. D. (1983) The molecular biology of platelet-derived growth factor. Cell 33, 653-655.

Stiles, C. D., Capone, G. T., Scher, C. D., Antoniades, H. N., Van Wyk, J. J. and Pledger, W. J. (1979) Dual control of cell growth by somatomedins and platelet-derived growth factor. Proc. Natl. Acad. Sci. USA 76, 1279-1283.

Sulzbacher, I., Traxler, M., Mosberger, I., Lang, S. and Chott, A. (2000) Platelet-derived growth factor-AA and -alpha receptor expression suggests an autocrine and/or paracrine loop in osteosarcoma. Mod. Pathol. 13, 632-637.

Sundberg, C., Branting, M., Gerdin, B. and Rubin, K. (1997) Tumor cell and connective tissue cell interactions in human colorectal adenocarcinoma. Transfer of platelet-derived growth factor-AB/BB to stromal cells. Am. J. Pathol. 151, 479-492.

Thommen, R., Humar, R., Misevic, G., Pepper, M. S., Hahn, A. W., John, M. and Battegay, E. J. (1997) PDGF-BB increases endothelial migration on cord movements during angiogenesis in vitro. J. Cell. Biochem. 64, 403-413.

Tsai, Y. J., Lee, R. K., Lin, S. P. and Chen, Y. H. (2000) Identification of a novel platelet-derived growth factor-like gene, fallotein, in the human reproductive tract. Biochim. Biophys. Acta 1492, 196-202.

Tzeng, D. Y., Deuel, T. F., Huang, J. S. and Baehner, R. L. (1985) Platelet-derived growth factor promotes human peripheral monocyte activation. Blood 66, 179-183.

Uhrbom, L., Hesselager, G., Ostman, A., Nister, M. and 
Westermark, B. (2000) Dependence of autocrine growth factor stimulation in platelet-derived growth factor-B-induced mouse brain tumor cells. Int. J. Cancer 85, 398-406.

Unlu, S., Mason, C. D. and Hughes, A. D. (1998) Platelet-derived growth factor-BB induces apoptosis in cultured vascular smooth muscle cells derived from human saphenous vein. Biochem. Soc. Trans. 26, S325.

Uutela, M., Lauren, J., Bergsten, E., Li, X., Horelli-Kuitunen, N., Eriksson, U. and Alitalo, K. (2001) Chromosomal location, exon structure, and vascular expression patterns of the human PDGFC and PDGFC genes. Circulation 103, 2242-2247.

Walker, R. A. (2001) The complexities of breast cancer desmoplasia. Breast Cancer Res. 3, 143-145.

Wang, D., Huang, H. J., Kazlauskas, A. and Cavenee, W. K. (1999) Induction of vascular endothelial growth factor expression in endothelial cells by platelet-derived growth factor through the activation of phosphatidylinositol 3-kinase. Cancer Res. 59, 1464-1472.

Waterfield, M. D., Scrace, G. T., Whittle, N., Stroobant, P., Johnsson, A., Wasteson, A., Westermark, B., Heldin, C. H., Huang, J. S. and Deuel, T. F. (1983) Platelet-derived growth factor is structurally related to the putative transforming protein p28sis of simian sarcoma virus. Nature 304, 35-39.

Westermark, B., Heldin, C. H. and Nister, M. (1995) Plateletderived growth factor in human glioma. Glia. 15, 257-263.

Westermark, B. and Wasteson, A. (1976) A platelet factor stimulating human normal glial cells. Exp. Cell. Res. 98, 170174.

Williams, L. T., Antoniades, H. N. and Goetzl, E. J. (1983) Platelet-derived growth factor stimulates mouse 3T3 cell mitogenesis and leukocyte chemotaxis through different structural determinants. J. Clin. Invest. 72, 1759-1763.

Yeh, H. J., Ruit, K. G., Wang, Y. X., Parks, W. C., Snider, W. D. and Deuel, T. F. (1991) PDGF A-chain gene is expressed by mammalian neurons during development and in maturity. Cell 64, 209-216.

Yokote, K., Hellman, U., Ekman, S., Saito, Y., Ronnstrand, L., Heldin, C. H. and Mori, S. (1998) Identification of Tyr-762 in the platelet-derived growth factor alpha-receptor as the binding site for Crk proteins. Oncogene 16, 1229-1239.

Yokote, K., Mori, S., Siegbahn, A., Ronnstrand, L., Wernstedt, C., Heldin, C. H. and Claesson-Welsh, L. (1996) Structural determinants in the platelet-derived growth factor alpha-receptor implicated in modulation of chemotaxis. J. Biol. Chem. 271, 5101-5111.

Yoneda, T. (1998) Cellular and molecular mechanisms of breast and prostate cancer metastasis to bone. Eur. J. Cancer 34, 240245.

Yu, J., Deuel, T. F. and Kim, H. R. (2000) Platelet-derived growth factor (PDGF) receptor-alpha activates c-Jun NH2-terminal kinase-1 and antagonizes PDGF receptor-beta -induced phenotypic transformation. J. Biol. Chem. 275, 19076-19082.

Yu, J., Moon, A. and Kim, H. R. (2001) Both platelet-derived growth factor receptor (PDGFR)-alpha and PDGFR-beta promote murine fibroblast cell migration. Biochem. Biophys. Res. Commun. 282, 697-700.

Zoltowska, A. (1997) Pathogenesis of breast carcinoma. Immunohistochemical study. Arch. Immunol. Ther. Exp. Warsz 45, 101-108. 